\title{
Finite Element Analysis of Reinforced Concrete Beams with Corrosion Subjected to Shear
}

\author{
Tanarat Potisuk, ${ }^{1}$ Christopher C. Higgins, ${ }^{2}$ Thomas H. Miller, ${ }^{2}$ and Solomon C. Yim ${ }^{2}$ \\ ${ }^{1}$ H.W. Lochner, Inc., 2001 Front Street NE No. 120, Salem, OR 97301, USA \\ ${ }^{2}$ School of Civil and Construction Engineering, Oregon State University, Corvallis, OR 97331, USA
}

Correspondence should be addressed to Thomas H. Miller, thomas.miller@oregonstate.edu

Received 19 January 2011; Accepted 20 March 2011

Academic Editor: Ayman Mosallam

Copyright (C) 2011 Tanarat Potisuk et al. This is an open access article distributed under the Creative Commons Attribution License, which permits unrestricted use, distribution, and reproduction in any medium, provided the original work is properly cited.

\begin{abstract}
Finite element (FE) modeling techniques were developed to isolate the different contributions of corrosion damage to structural response of experimental reinforced concrete beams with shear-dominated behavior. Corrosion-damage parameters included concrete cover spalling due to the expansion of corrosion products; uniform stirrup cross-sectional loss from corrosion; localized stirrup cross-sectional loss due to pitting; debonding of corrosion-damaged stirrups from the concrete. FE analyses were performed including both individual and combined damages. The FE results matched experimental results well and quantitatively estimated capacity reduction of the experimental specimens.
\end{abstract}

\section{Introduction}

Many conventionally reinforced concrete (CRC) structures are exposed to conditions that can lead to corrosion of the embedded reinforcing steel. These include coastal structures subjected to wind-born salt spray and seawater as well as bridges subjected to deicing salt. Engineers often must evaluate existing structures that exhibit corrosion-induced damage, and only limited information is available for condition assessment and structural evaluation. A tool that has become widely used for analysis of structures is finite element analysis; however, application to corrosion-damaged structures requires modeling assumptions. Assessment of the sensitivity of results to the modeling assumptions requires parametric study and validation with experimental results. This paper presents modeling details for finite element analysis of CRC beams with corrosion damage to shear reinforcement and provides comparison of analyses with large-scale experiments on beam specimens for a range of corrosion-damaged components.

Previous research on the effects of corrosion damage has focused on flexural behavior of reinforced concrete (RC) members [1-4], the effects of corrosion on the bond behavior of corroded rebar $[5,6]$, and the effects of cross-section loss due to corrosion on the mechanical properties of rebar $[7,8]$. Previous research on the effects of corrosion on shear behavior of RC beams is lacking. An experimental study on the capacity assessment of RC beams with corrosion damage to the transverse steel was accomplished [9]. This research focused on the behavior of RC beams exhibiting various levels of corrosion damage to the transverse steel. Detailed experimental observations as well as applications of traditional analysis techniques to predict capacity are presented in the works of Higgins and Farrow III [10] and Higgins et al. [11]. These beam specimens were used to aid the development of finite element modeling techniques, and for comparison with parametric analyses to identify the contributions of damage components to capacity reduction.

Finite element analysis has been widely used in engineering applications. FE analysis of concrete structures has been performed using a number of different concrete models, with one of the most common being the smeared cracking approach. The method was employed for behavior evaluation of RC members [12-17]. Dagher and Kulendran [18] used the smeared cracking approach to develop a numerical model for corrosion damage in concrete that provided a better understanding of mechanisms of damage propagation, spalling, and delamination. Coronelli and Gambarova [19] 
employed nonlinear finite element analysis for structural assessment of corroded RC beams that exhibited a flexural failure. The effects of corrosion were modeled by reducing the geometry of concrete and steel rebar elements and by modifying the constitutive models of concrete and steel as well as bond between the two materials. The approach applied to analysis of concrete beams with corrosion damage to transverse reinforcement for structural capacity prediction is new.

This study uses a commercially available finite element code. Experimental specimens $[10,11]$ are used for comparison of results, and the individual contributions of cover spalling due to expansion of corrosion products, rebar debonding from the concrete, and cross-sectional area loss from corrosion are isolated and combined to predict the relative contributions to strength and deformation capacity reduction.

\section{Research Significance}

Prior research on the effects of corrosion damage has focused on flexural behavior of RC members and bond behavior of corroded rebars. Research on the effects of corrosion on shear behavior of RC beams is lacking. This paper presents analysis methods using finite element modeling for structural evaluation of shear-dominated RC beams subjected to corrosion damage. The modeling techniques may be used by structural engineers to determine the impact of corrosion damage components on capacity for shear-dominated beams.

\section{Experimental Beams}

Fourteen reinforced concrete beam specimens with different levels of corrosion damage were tested to failure $[10,11]$. The experimental beams were designed to reflect 1950's bridge girder proportions based on reviews of several CRC bridges and the design specification of the time. The design proportions were chosen to represent cross-sectional properties for a shear-critical section, at a distance approximately the effective depth from the support. The test setup was designed to result in a diagonal-tension failure of one of the test spans. The span-to-depth ratio was 2.0.

The experimental beams without corrosion damage were used to develop modeling techniques and for validation of the finite element (FE) analyses results $[10,11,17]$. The FE models were then employed to investigate effects of corrosion damage using a series of rectangular section beams. The four experimental beams had the same design properties, as shown in Figure 1, but were subject to different corrosion damage levels. The beams consisted of four corroded stirrups in the test span, with a spacing of $254 \mathrm{~mm}$. To ensure failure in the section of interest, tighter stirrup spacing $(152 \mathrm{~mm})$ was used on the uncorroded half of the span. An accelerated corrosion process was applied to the beam specimens using the corrosion cell to pass current through the stirrups acting as the anode. The corrosion cell consisted of a galvanized wire mesh acting as the cathode. Mesh was placed on the sides and bottom of the beams. The stirrups were connected in parallel to a constant current supply. Corrosion damage was prevented from occurring on the flexural steel. A wetted cotton towel was placed between the galvanized wire mesh and the concrete surface to provide electrical contact. Current was impressed through the stirrups at a constant current density. The degree of corrosion damage was controlled by the exposure time for the given current for each specimen.

During the accelerated corrosion process, cracks due to corrosion were mapped and recorded. Delaminations and spalled areas of concrete cover in the test spans were also identified. Although the damaged specimens showed similar visual corrosion including extensive cover cracking, delaminations, and rust staining, each of the four experimental beams exhibited different amounts of stirrup damage estimated by monitoring current flow into the stirrups. The specimens ranged from no damage to severe damage and were designated as specimen 10RA, 10RB, 10RC, and 10RD. Specimen 10RA had no corrosion damage. Specimens 10RB, 10RC, and 10RD had light, moderate, and severe damage states, respectively. Typically, cracks were observed adjacent to locations of the corroded stirrups, along the stem face to top and bottom of the beams, and near the location of the longitudinal steel, even though the flexural steel was not corroding.

Prior to testing, the experimental beams were visually inspected for damage and rated according to the Oregon Department of Transportation (ODOT) Bridge Inspection Pocket Coding Guide [20] that corresponds to national bridge inspection (NBI) guidelines [21]. The experimental beams were rated for item no. 110-Open Girder/Beam and NBI item \#59. Superstructure item no. 110 rating values range from 1 to 4 , with 1 representing little or no damage and 4 representing advanced deterioration. NBI item no. 59 rating values range from 9 to 0 , with 9 representing excellent condition and 0 representing a failed condition. The rating value for item \#110 was 3 for all damaged specimens. For NBI Item \#59, specimens 10RB, 10RC, and 10RD were given a rating value of $5,5 / 4$, and 4 , respectively. Note that these rating values were similar between specimens although corrosion levels were different.

Beams were tested to failure using a monotonic loading protocol in a load frame as shown in Figure 2. The specimens exhibited shear-compression failures in the test span. Loaddeflection responses for the experimental beams are shown in Figure 3. Maximum load, midspan deflection at the maximum load, and the amount of energy absorbed for each of the experimental beams are shown in Table 1. Experimental results showed that ultimate strength was reduced for larger amounts of corrosion damage, with specimens 10RB, 10RC, and 10RD exhibiting 12\%,19\%, and 30\% lower ultimate strength, respectively, than specimen 10RA. The amount of energy absorbed by the beams was also used for specimen comparisons, taken as the area under the load-deflection curve starting from initial loading to the maximum load before unloading. Specimens 10RB, 10RC, and 10RD had $24 \%, 47 \%$, and $55 \%$ reduced energy, respectively, compared to specimen 10RA.

After failure, test specimens were examined and observations were made. The core region remained intact, while 


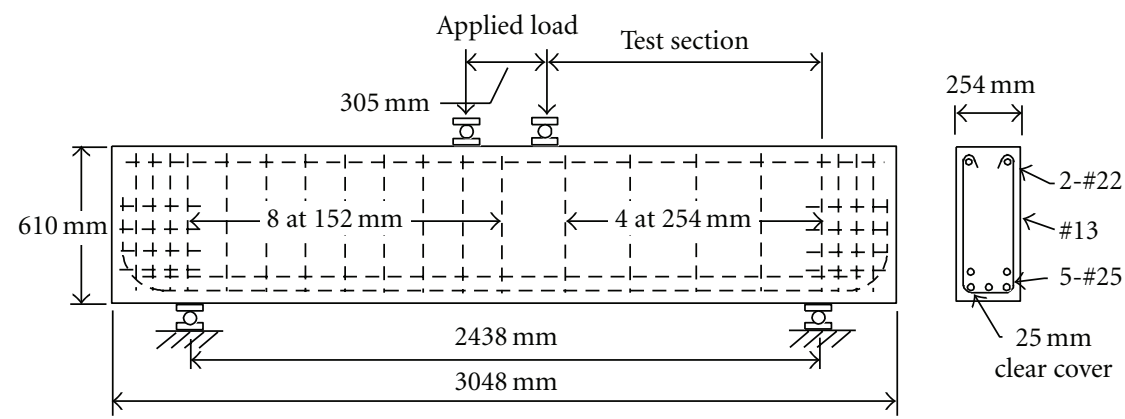

FIGURE 1: Experimental specimen configuration.

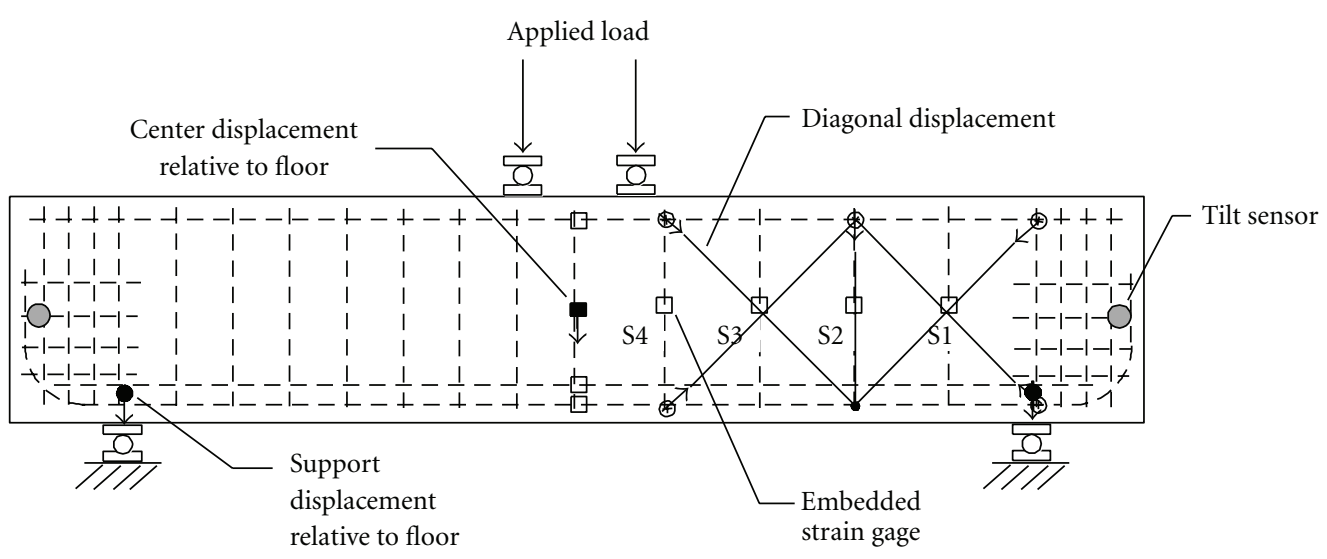

Figure 2: Test setup.

much of the cover concrete was effectively delaminated. In the corrosion-damaged specimens, separation between the concrete core and cover was observed. A measurement of cover thickness was taken, and the average cover thickness was approximately $25 \mathrm{~mm}$ ( $1 \mathrm{in}$.), close to the specified concrete clear cover. Stirrups that crossed the diagonal failure crack were removed from each specimen. Measurements of the remaining cross-sectional areas for the corroded stirrups were made. Both uniform cross-section loss along the leglength and local maximum section loss were determined for the corroded stirrups. Mean values for the uniform crosssection loss along the stirrup legs and the local maximum section losses were $13 \%$ and $34 \% ; 23 \%$ and $61 \% ; 26 \%$ and $100 \%$ for the 10RB, 10RC, and 10RD beams, respectively. Table 2 shows the measured cross-sectional areas and area losses for the stirrups after testing.

\section{Finite Element Analysis}

Finite element analyses were performed to predict the response of the previously described experimental specimens. These beam specimens were used to aid the development of finite element modeling techniques and for comparison with parametric analyses to identify the contributions of damage components to capacity reduction. After validation of the model for the undamaged specimen, corrosion damage was introduced to the FE models. Subsequently, corrosion damage components were analyzed in isolation (i.e., concrete cover spalling, stirrup cross-sectional loss, and debonding at concrete-rebar interfaces). This enabled the identification of the contribution of corrosion damage constituents to structural performance deterioration.

4.1. Model Description. FE analyses of the beam specimens were performed using ANSYS version 7.1 [22], and the finite element model is shown in Figure 4. For reinforced concrete, the 3D solid element, SOLID65 in ANSYS, had eight nodes and three degrees of freedom at each node, translations in the nodal $x, y$, and $z$ directions. This element is capable of plastic deformation, crushing, and cracking in three orthogonal directions at each integration point. The solid element simulated concrete cracking with a smeared cracking approach. A 3D truss element, LINK8 in ANSYS, consisted of two nodes and three degrees of freedom at each node, translations in the nodal $x, y$, and $z$ directions, and is used to model the discrete steel reinforcement. For the specimens considered, only half of the experimental beam was modeled due to symmetry. Embedded reinforcing steel was modeled using nonlinear truss elements rigidly connected to the surrounding concrete elements representing a perfect bond between concrete and reinforcing steel. For some of the later corrosion models, truss elements were not rigidly connected to the surrounding concrete elements as will be described later. Analyses were performed using a quasidisplacement control technique that incorporated high-stiffness springs at the loading point locations to accelerate solution times 


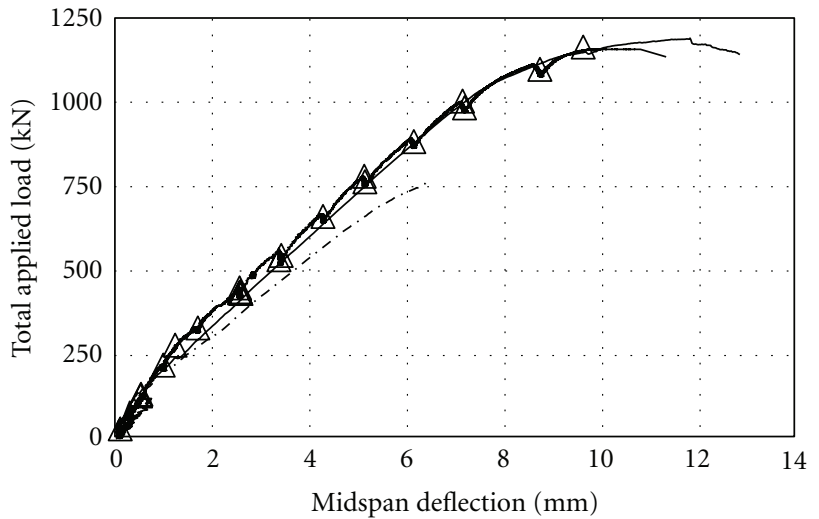

(a)

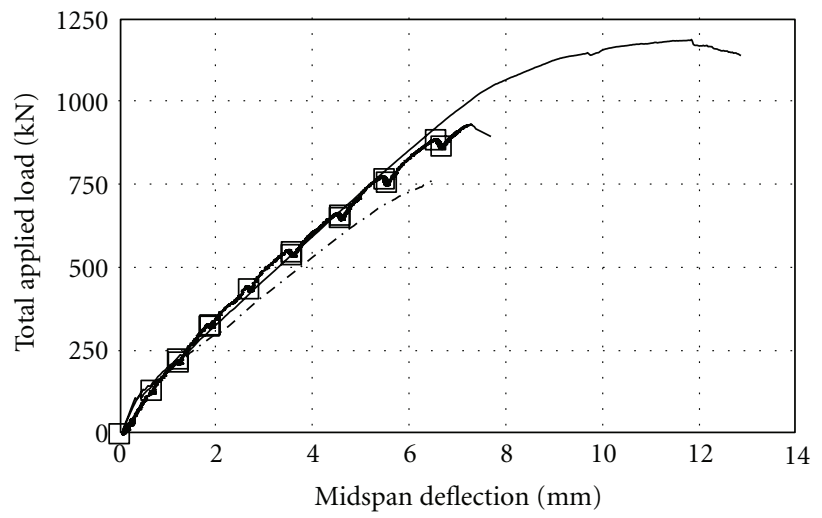

$\triangle$ EXP-10RA

$\bigcirc$ EXP-10RB

$\square$ EXP-10RC

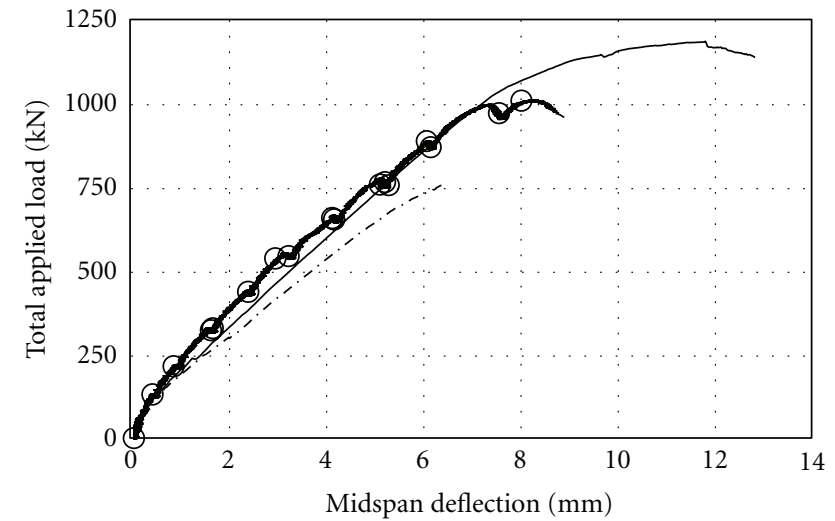

(b)

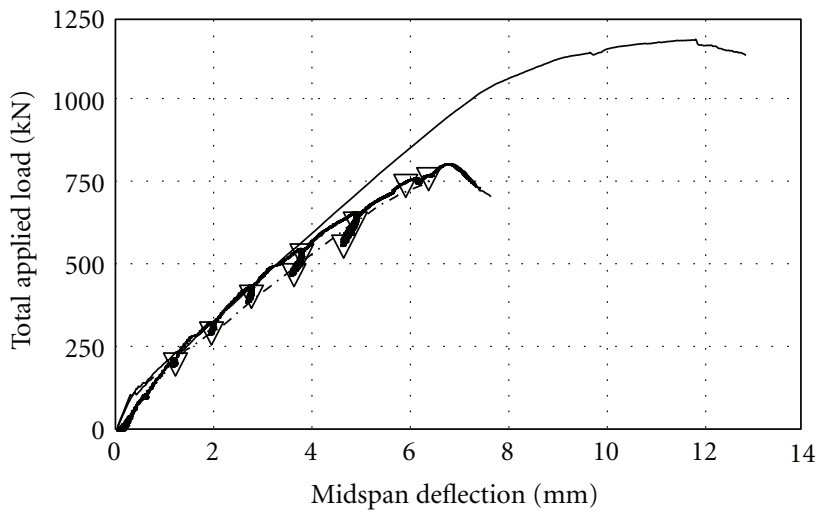

$\triangle$ EXP-10RA

- - EXP-10RB

$\square$ EXP-10RC $\nabla$ EXP-10RD

— FE-No spall, 0\% A, loss

-..- FE-Spall, $100 \%$ A, loss

(d)

FIGURE 3: Load-deflection response for experimental results and FE models.

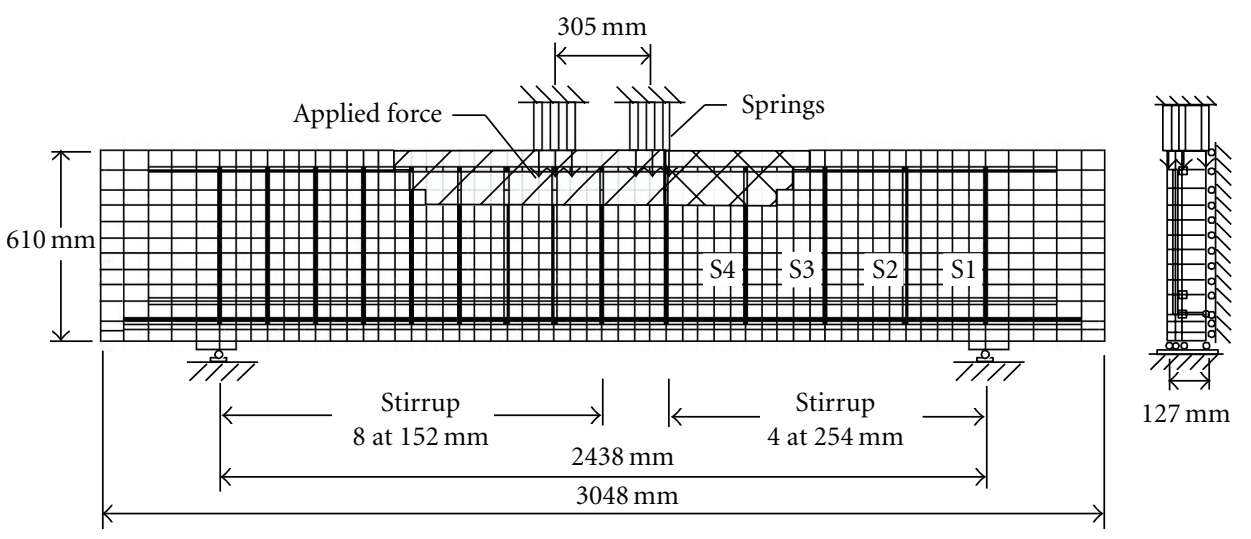

$7 /$ Confined concrete with $152 \mathrm{~mm}$ spacing

\. Confined concrete with $254 \mathrm{~mm}$ spacing

FIgURE 4: Finite element model for undamaged beam specimens. 
TABLE 1: Summary of experimental and finite element modeling results.

\begin{tabular}{|c|c|c|c|}
\hline Experimental beam & Max. load $(\mathrm{kN})$ & Deflection at max. load $(\mathrm{mm})$ & Energy $(\mathrm{kN} \cdot \mathrm{m})$ \\
\hline 10RA & 1158 & 10.3 & 7.5 \\
\hline $10 \mathrm{RB}$ & 1014 & 8.3 & 5.7 \\
\hline $10 \mathrm{RC}$ & 935 & 7.3 & 4.0 \\
\hline $10 \mathrm{RD}$ & 813 & 6.8 & 3.4 \\
\hline \multicolumn{4}{|l|}{ Finite element model } \\
\hline \multicolumn{4}{|c|}{ No spall (254 mm effective width) $w /$ bonded concrete-rebar interface } \\
\hline $0 \% A_{s}$ loss (no corrosion damage) & 1190 & 11.8 & 9.1 \\
\hline $50 \% A_{s}$ loss & 1112 & 9.7 & 6.5 \\
\hline $100 \% A_{s}$ loss & 819 & 6.6 & 3.1 \\
\hline \multicolumn{4}{|c|}{ Spall (203 mm effective width) $w /$ bonded concrete-rebar interface } \\
\hline $0 \% A_{s}$ loss & 1061 & 8.9 & 5.5 \\
\hline $50 \% A_{s}$ loss & 1029 & 8.5 & 5.0 \\
\hline $100 \% A_{s}$ loss & 800 & 6.9 & 3.2 \\
\hline SP2 (0\% uniform, 75\% local maximum) & 1050 & 9.3 & 5.8 \\
\hline \multicolumn{4}{|l|}{ Spall $w /$ debonded concrete-rebar interface } \\
\hline $0 \% A_{s}$ loss with spalled cover & 920 & 7.8 & 4.2 \\
\hline $50 \% A_{s}$ loss with spalled cover & 918 & 8.3 & 4.6 \\
\hline SP2 (0\% uniform, 75\% local maximum) & 853 & 7.1 & 3.5 \\
\hline SP2 (50\% uniform, $75 \%$ local maximum) & 806 & 7.0 & 3.4 \\
\hline
\end{tabular}

TABLE 2: Uniform and local maximum cross-sectional losses for experimental stirrup specimens.

\begin{tabular}{|c|c|c|c|c|c|}
\hline \multirow{2}{*}{ Specimen } & & \multicolumn{2}{|c|}{ Uniform } & \multicolumn{2}{|c|}{ Local maximum } \\
\hline & & Area $\left(\mathrm{mm}^{2}\right)$ & $\%$ Section loss & Area $\left(\mathrm{mm}^{2}\right)$ & $\%$ Section loss \\
\hline \multirow{5}{*}{$10 \mathrm{RB}$} & S2-1 & 111.0 & 14.0 & 96.0 & 25.6 \\
\hline & S2-2 & 112.6 & 12.7 & 107.0 & 17.1 \\
\hline & S3-1 & 114.0 & 11.7 & 85.0 & 34.1 \\
\hline & S3-2 & 110.3 & 14.6 & 87.0 & 32.6 \\
\hline & & Avg. & 13.2 & & \\
\hline \multirow{5}{*}{$10 \mathrm{RC}$} & S2-1 & 102.1 & 20.9 & 100.0 & 22.5 \\
\hline & S2-2 & 91.8 & 28.9 & 50.0 & 61.3 \\
\hline & S3-1 & 103.7 & 19.7 & 92.9 & 28.0 \\
\hline & S3-2 & 99.4 & 23.0 & 78.0 & 39.6 \\
\hline & & Avg. & 23.1 & & \\
\hline \multirow{5}{*}{ 10RD } & S2-1 & 80.6 & 37.5 & 0.0 & 100.0 \\
\hline & S2-2 & 72.5 & 43.9 & 29.7 & 77.0 \\
\hline & S3-1 & 111.9 & 13.3 & 104.5 & 19.0 \\
\hline & S3-2 & 118.1 & 8.5 & 101.9 & 21.0 \\
\hline & & Avg. & 25.8 & & \\
\hline
\end{tabular}

without loss of precision. This acceleration technique is described in detail by Potisuk [17]. Ends of the linear spring elements with high stiffness were connected between loading nodes of the beam model and a fixed boundary condition. Incremental forces were gradually applied to the end nodes of the spring elements, controlling the displacement of the model. The resulting forces are computed based on support reactions. Displacement loading ranged between $0.02 \mathrm{~mm}$ and $0.10 \mathrm{~mm}$ depending on the degree of nonlinearity.

4.2. Materials. Material properties used in the model for both the concrete and reinforcing steel were based on mech- anical tests. Constitutive modeling of the concrete was performed using Todeschini's [23] approximation for the compressive stress-strain relationship with parameters based on best fit of actual cylinder compression tests as shown in Figure 5. The compressive stress-strain curve was defined to model concrete crushing, instead of using the crushing capability of the solid element. Concrete strengths $\left(f^{\prime}{ }_{c}\right)$ for specimens 10RA, 10RB, 10RC, and 10RD at the day of test were $34.1,34.6,35.2$, and $30.3 \mathrm{MPa}$, respectively. The average of these concrete strengths was $33.1 \mathrm{MPa}$ and was used for all models to facilitate the comparison of results for the parametric study. An average strain at the peak stress $\left(\varepsilon_{o}\right)$ 


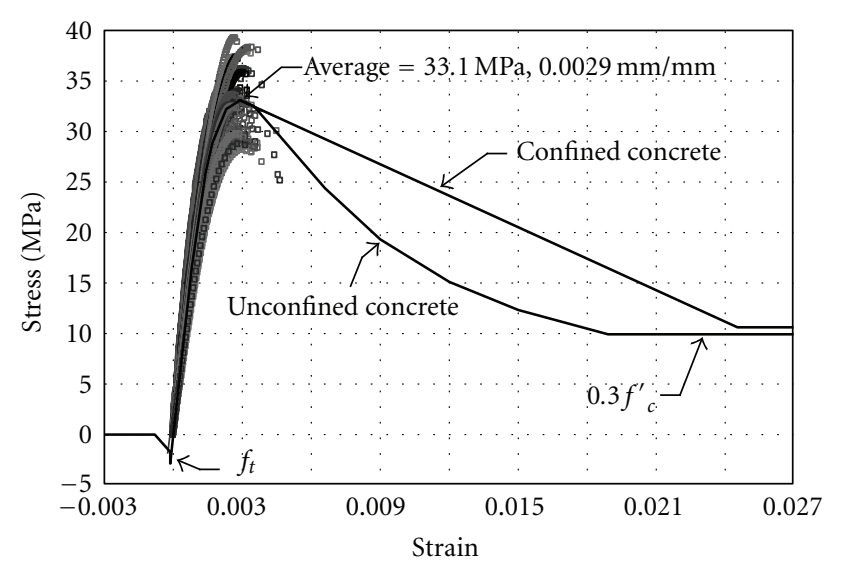

- EXP

FEM

FIgURE 5: Stress-strain relationship for concrete modeling.

of $0.0029 \mathrm{~mm} / \mathrm{mm}$, also obtained from the compression tests, was used to construct the concrete stress-strain curve. Tensile strength $\left(f_{t}\right)$ was set at $0.5 \sqrt{f^{\prime}{ }_{c}} \mathrm{MPa}\left(6 \sqrt{f^{\prime}{ }_{c}} \mathrm{psi}\right)$, and Poisson's ratio was taken as 0.2 . To account for confining effects at the load application points, concrete elements near midspan (Figure 4) were modified to permit slower postpeak decay in compressive stress, at support and loading locations $[24,25]$.

Stress-strain relationships for the reinforcing steel were obtained by tension tests using a $51 \mathrm{~mm}$ gage length. Bilinear curves were employed for steel material modeling. Reinforcing steel had a yield stress of $496 \mathrm{MPa}$ for the flexuraltension rebars and $483 \mathrm{MPa}$ for the flexural-compression rebars. Stirrups had a yield stress of $441 \mathrm{MPa}$. Stress-strain curves for steel reinforcement are shown in Figure 6.

4.3. Finite Element Model Validation without Corrosion Damage. A baseline, model without corrosion damage was developed (Figure 4). Results from the finite element analysis were compared with experimental response from specimen 10RA. As shown in Figure 3, the overall load-deflection response of the finite element model without corrosion damage compared well with the experimental response. The ultimate capacity and energy of the FE model (with no corrosion damage) were $3 \%$ and $21 \%$ higher, respectively, than those of specimen 10RA (Table 1). In addition to the ultimate load and energy comparisons, the analytically predicted "crack pattern" considering maximum principal-tension strains was compared with the observed crack pattern at failure for the experimental beam. As shown in Figure 7(a), the predicted and experimental crack patterns were similar. In addition to the global response, localized reinforcing steel strain responses were also compared. Strains in the flexural steel for the undamaged model and experimental specimen 10RA are shown in Figure 8(a). Flexural reinforcing bars in the FE model and experimental specimen 10RA both achieved the yield strain. The interior lower-layer (LL-I) rebar yielded at a load of $1023 \mathrm{kN}$ for the FE model and at a load of $907 \mathrm{kN}$ for specimen 10RA a 13\% difference. The upper-layer (UL) rebar yielded at a load of $1134 \mathrm{kN}$ for the model and at a load of $1036 \mathrm{kN}$ for specimen 10RA a 9\% difference. Analytically predicted and experimentally measured stirrup strains are shown in Figure 8(b). Two stirrups within the test span were identified as yielded for both the FE model and experimental specimen 10RA. However, the yielded stirrups in the FE model were stirrups S1 and S2 (Figure 4), while the yielded stirrups in the experimental specimen 10RA were stirrups S2 and S3. This difference may be due to actual discrete crack locations relative to strain gage locations, and bond stresses adjacent to these crack locations for the experimental specimen compared to the smeared cracking and perfect bond conditions of the FE model. However, the overall and local responses of the experimental specimen were well predicted by the finite element model.

4.4. Finite Element Modeling of Corrosion Damage. Corrosion of embedded reinforcing steel produces damage to the concrete cover from expansion of the corrosion products as well as the reduction in the reinforcing steel area. FE modeling of corrosion damage was performed by considering both concrete cover damage and cross-sectional area loss to the transverse steel. These components were treated individually and also combined. Corrosion damage to the stirrups was modeled in several ways. These included reducing the area of the stirrup elements over the entire stirrup leg length to represent uniform cross-sectional area loss and reducing the stirrup area for a specific stirrup element location to represent a locally reduced cross-sectional area. Different locations for the locally reduced areas were considered to determine the effect on response. Lastly, the impact of bond loss between the stirrups and concrete was considered by only attaching the coincident nodes for the stirrup and concrete elements at the top and bottom of the stirrup, instead of at every node.

At the extreme end of the life of the specimen, the concrete cover and the transverse steel area is fully lost. To model these severe corrosion damage conditions, an FE model was developed by removing the $25 \mathrm{~mm}$ thick concrete elements at the outside layer (as shown in Figure 9) and eliminating all four of the stirrup truss elements within the test span. The maximum load and energy of the severely damaged model (spall with $100 \% A_{s}$ loss in Table 1) are $33 \%$ and $65 \%$ lower, respectively, than those of the undamaged model. The ultimate capacity and energy of the severely damaged model were $800 \mathrm{kN}$ and $3.2 \mathrm{kN} \cdot \mathrm{m}$, which are $2 \%$ and $6 \%$ lower, respectively, than those of specimen 10RD. Loaddeflection response of the severely damaged model is shown in Figure 3. Analytically predicted crack patterns based on maximum principal strains and the experimentally observed cracking for specimen 10RD are shown in Figure 7(b). One large crack was observed for experimental specimen 10RD, while a wider band of large principal strains is seen in the FE model. Flexural and stirrup strains for experimental specimen $10 \mathrm{RD}$ were not collected due to damage to the strain gages during the corrosion process, and thus no comparisons could be made between experimental specimen and analytical model. Results from both the undamaged model and severely damaged models corresponded well with experimental results for specimens 10RA and 10RD and 

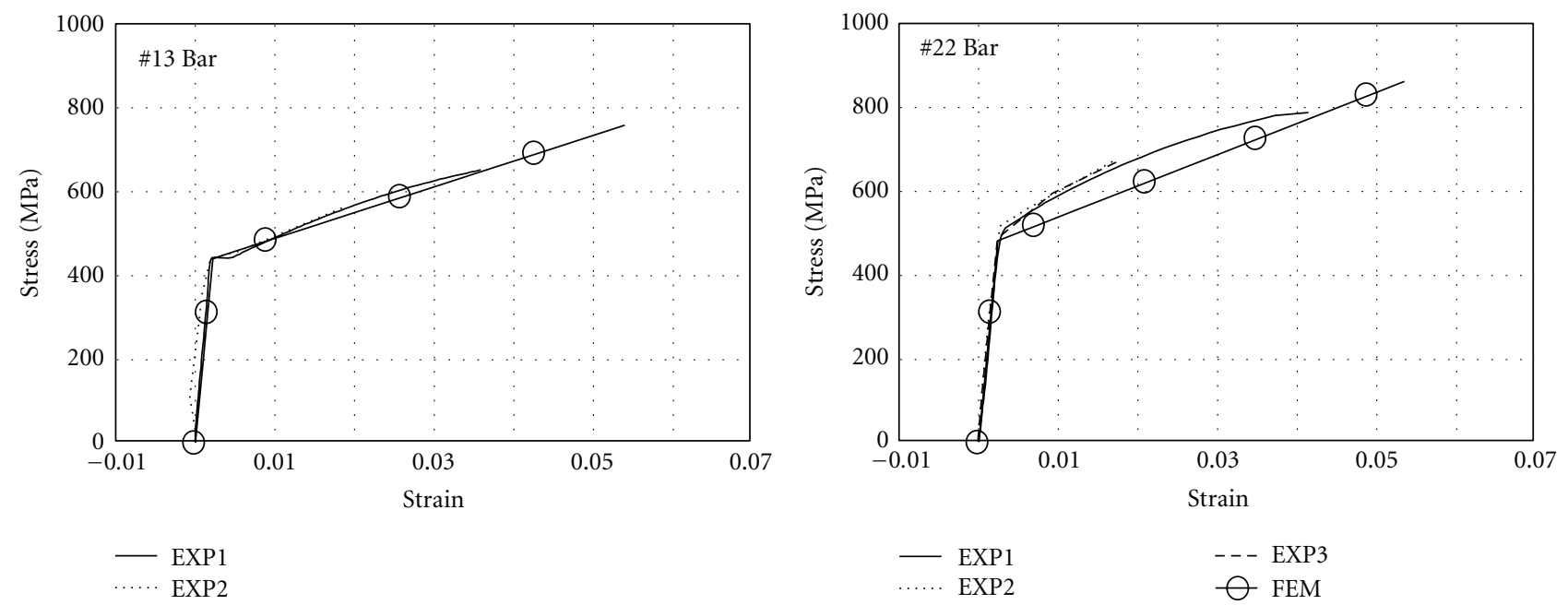

- EXP1
- EXP2
FEM

(a)

(b)

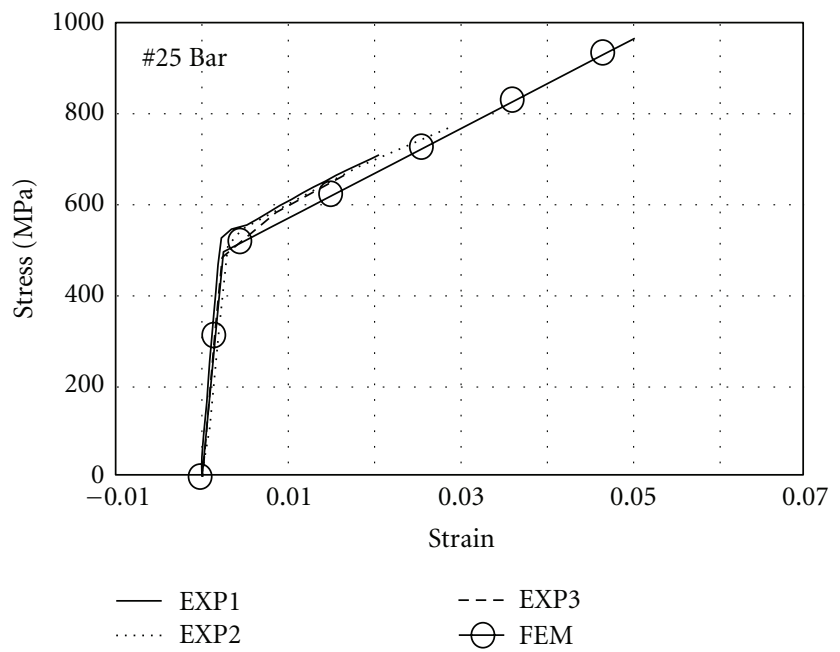

(c)

FIGURE 6: Stress-strain relationship for steel reinforcing bar modeling.
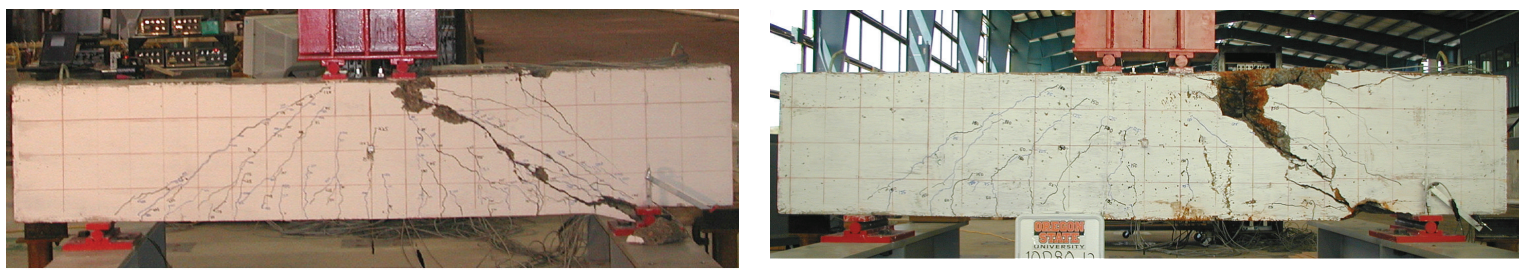

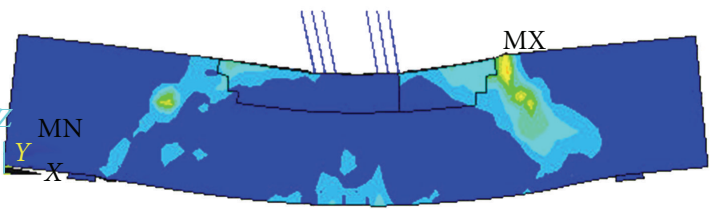

(a)

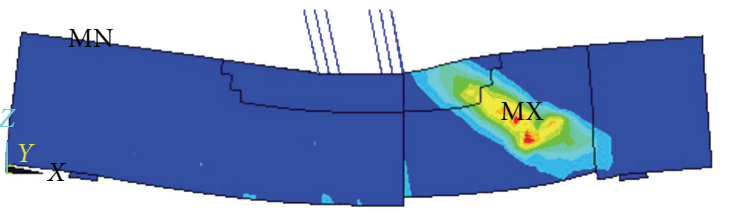

(b)

FIGURE 7: Crack patterns at failure: (a) specimen 10RA and undamaged FE model and (b) specimen 10RD and severely corroded FE model. 


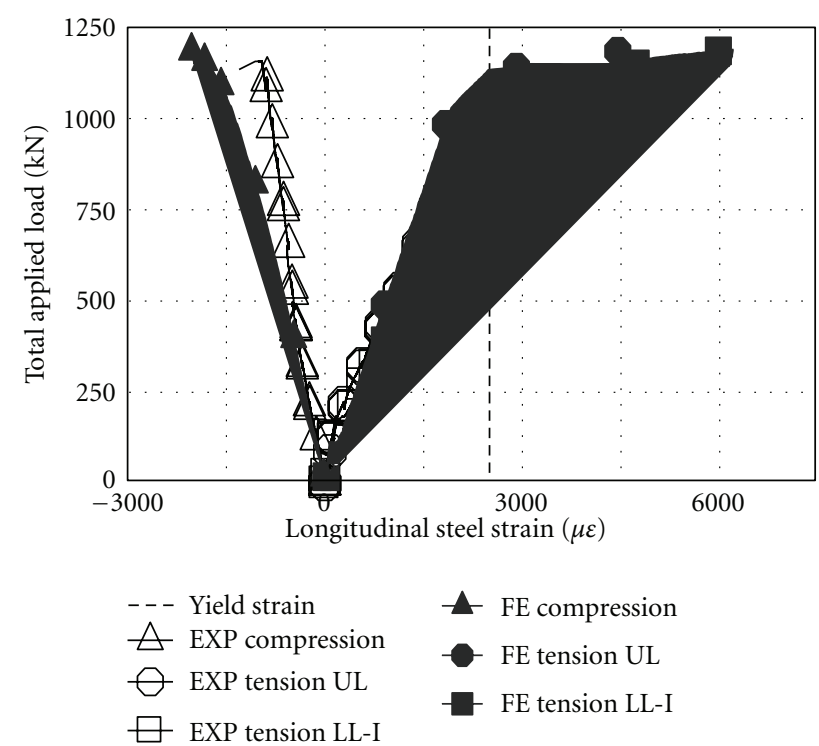

(a)

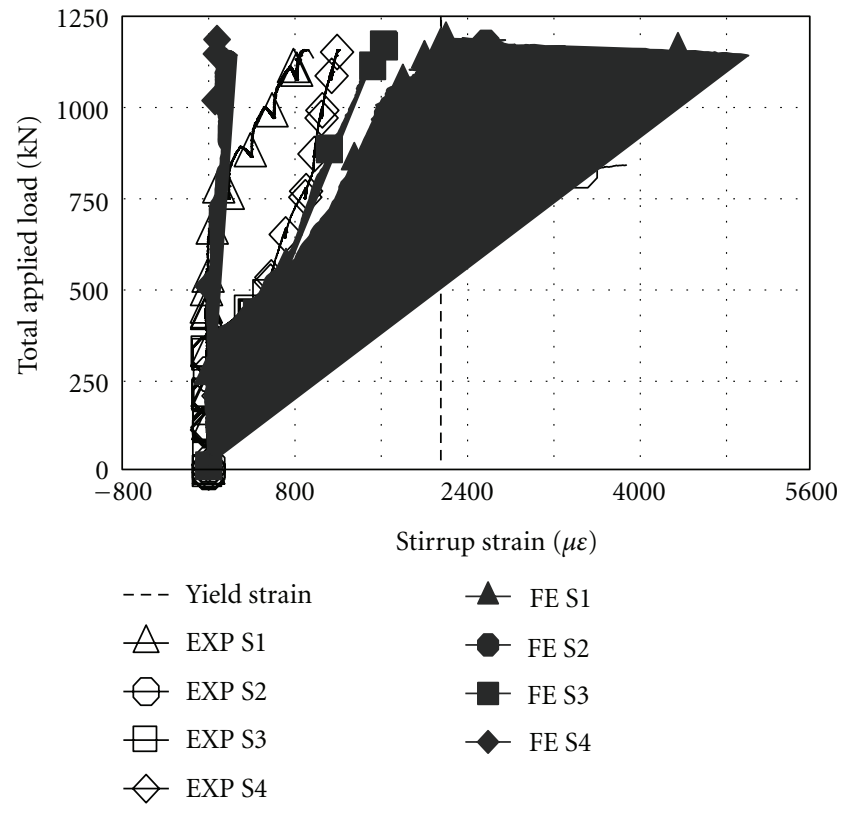

(b)

FIGURE 8: Experimental and predicted load-steel strain plots for (a) flexural steel and (b) stirrups for specimen 10RA and corresponding undamaged FE model.

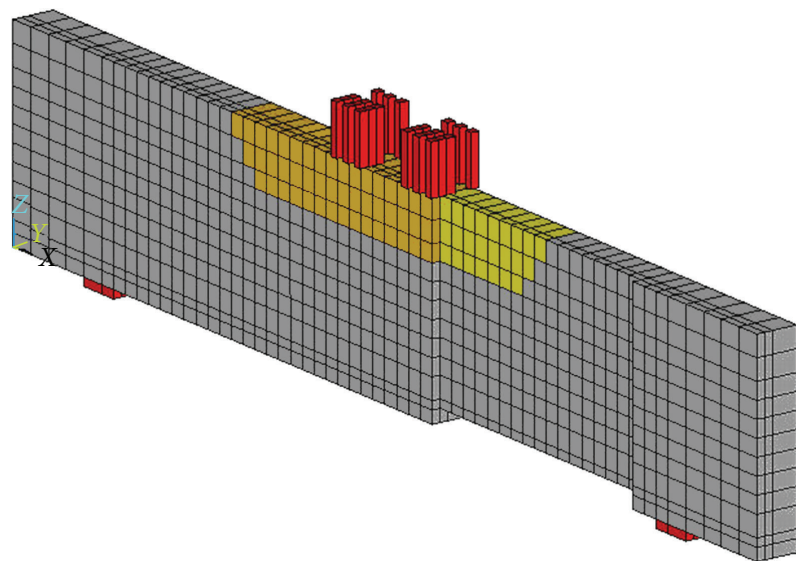

FIGURE 9: Corrosion-damaged finite element model with idealized concrete damage.

represented the upper and lower boundaries of the damage states.

To assess the isolated contribution of concrete cover spalling due to corrosion, the outside layer of concrete elements was removed, while the stirrup elements were included in the model and connected to the adjacent concrete elements at the nodes. Analysis results showed that the maximum load and energy of the model (spall $w /$ bonded concrete-rebar interface $w / 0 \% A_{s}$ loss in Table 1) were reduced by $11 \%$ and $40 \%$, respectively, as compared to the undamaged model.

To assess the role of uniform cross-sectional area loss, FE models with reduced cross-sectional areas for the stirrup elements were developed. No cover spalling was included to isolate the contribution of uniform stirrup cross-sectional loss on beam capacity. The areas of the stirrup truss elements in the test span were reduced by $50 \%$ and $100 \%$ uniformly over the entire leg length. FE results showed that the ultimate strength and energy of the models were $7 \%$ and $29 \%$ lower, respectively, for the $50 \%$ uniform cross-sectional area loss model and 31\% and 66\% lower, respectively, for the 100\% uniform cross-sectional area loss model as compared to the undamaged FE model.

In most cases, rebar area loss from corrosion occurs simultaneously with concrete cover spalling. To assess this interaction, a model with a combination of stirrup crosssectional area loss and concrete cover spalling was developed. Three uniform cross-sectional area losses of $0 \%, 50 \%$, and $100 \%$ were considered. The concrete cover was removed for these analyses. Due to the large volume expansion of corrosion products, the concrete cover would be significantly damaged for the amount of cross-sectional area loss considered $(50 \%$ and $100 \%)$. Predicted load-deflection responses of the combined damage models were compared with similar models without concrete cover spalling for the $0 \%, 50 \%$, and $100 \%$ cross-sectional area losses as shown in Figure 10. Comparisons of the ultimate load between the two series of model are shown in Figure 11(a). The reductions in ultimate load for the models without cover spalling and the models with cover spalling exhibited similar trends. There was a nonlinear reduction in ultimate load as the uniform stirrup cross-sectional area loss in the models increases. For the models without cover spalling and those with cover spalling, reductions in ultimate loads of $7 \%$ and $3 \%$, respectively, were found when the uniform cross-sectional area loss increased from $0 \%$ to $50 \%$. Similarly, reductions in ultimate load capacity of $26 \%$ and $22 \%$, respectively, were observed when the uniform cross-sectional area loss increased from 50\% 


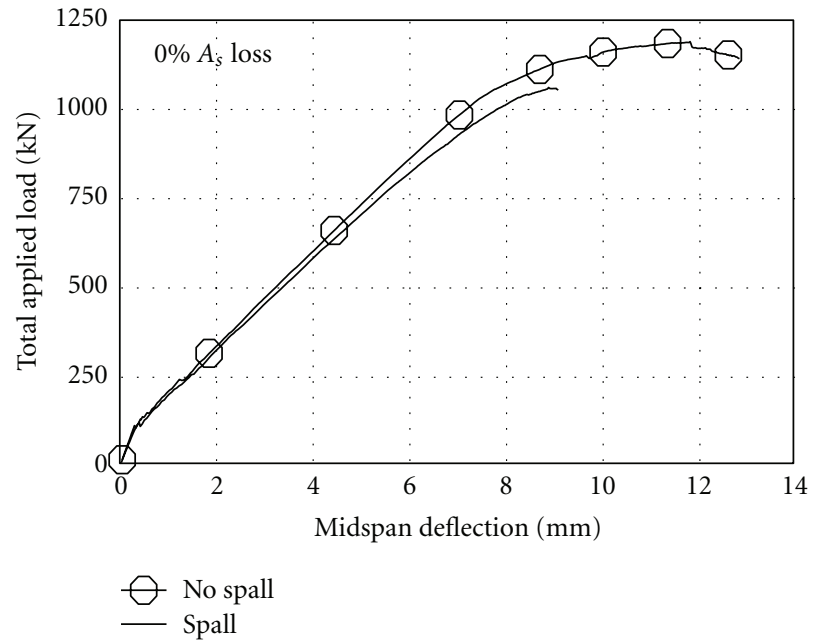

(a)

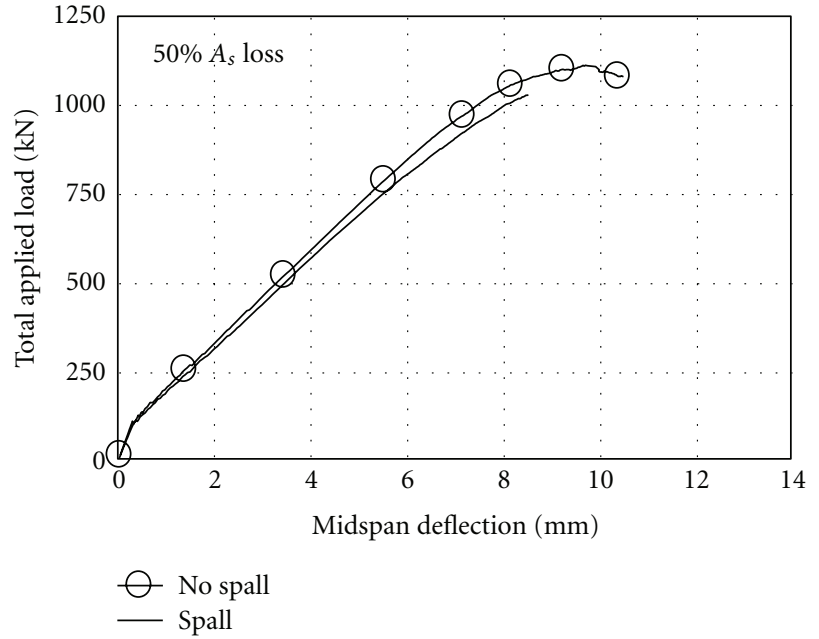

(b)

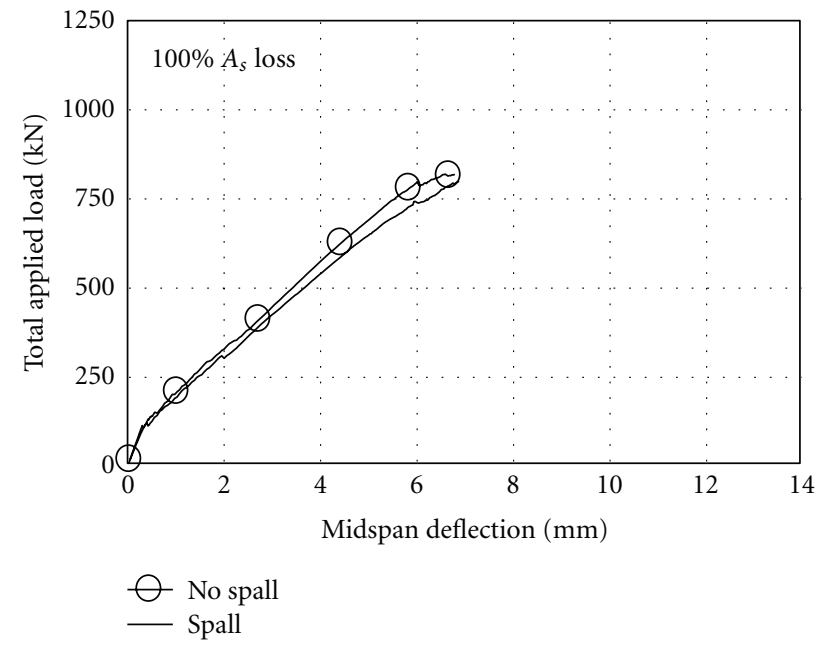

(c)

FIGURE 10: FE predicted load-deflection response for models with and without cover spalling and with $0 \%, 50 \%$, and $100 \%$ uniform stirrup cross-sectional loss.

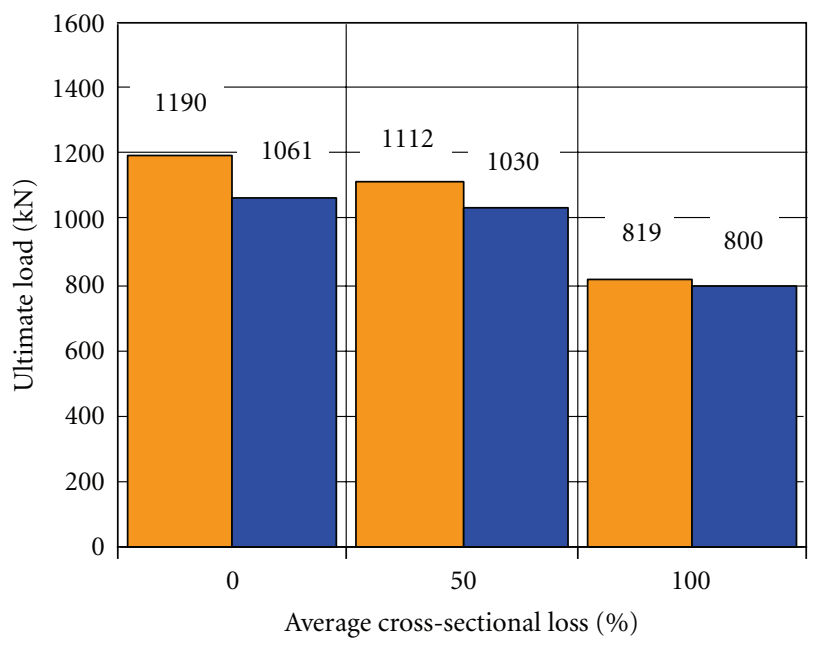

(a)

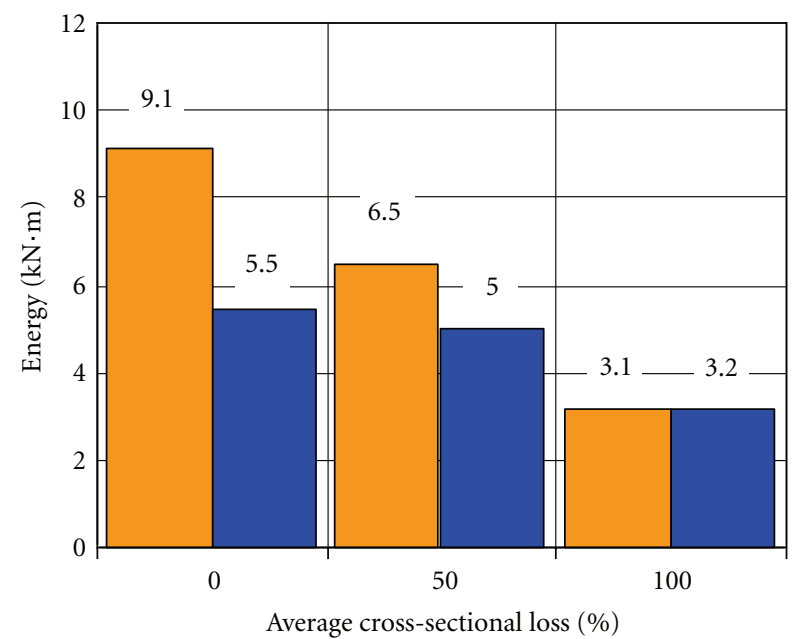

(b)

FIGURE 11: FE summary result for no-spall (yellow) and spall (blue) models: (a) ultimate load and (b) energy. 


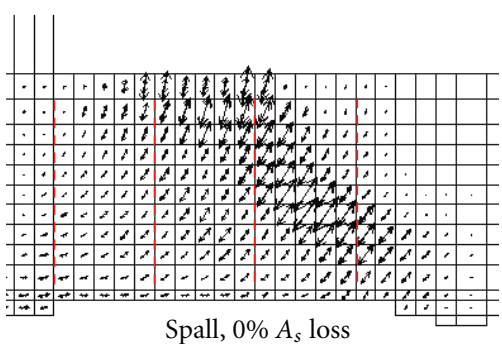

(a)

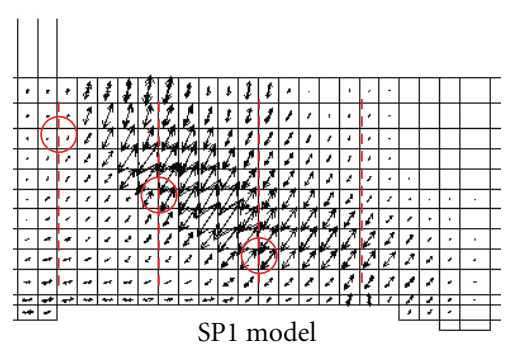

(b)

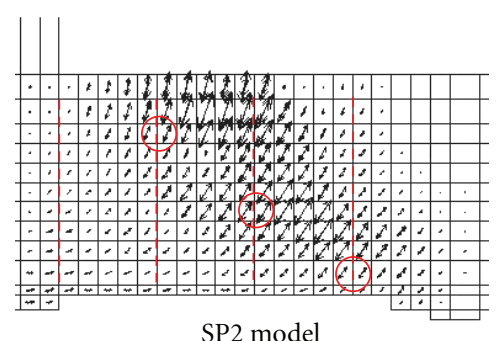

(c)

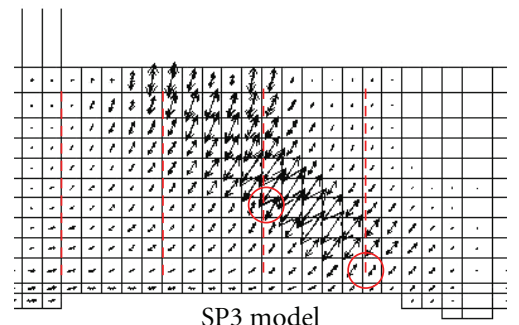

SP3 model

Stirrup location

Local maximum section loss location

(d)

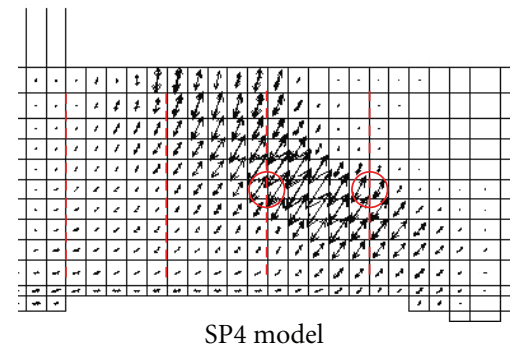

Stirrup location

Local maximum section loss location

(e)

FIGURE 12: FE models with spatially distributed, local maximum section loss in stirrups.

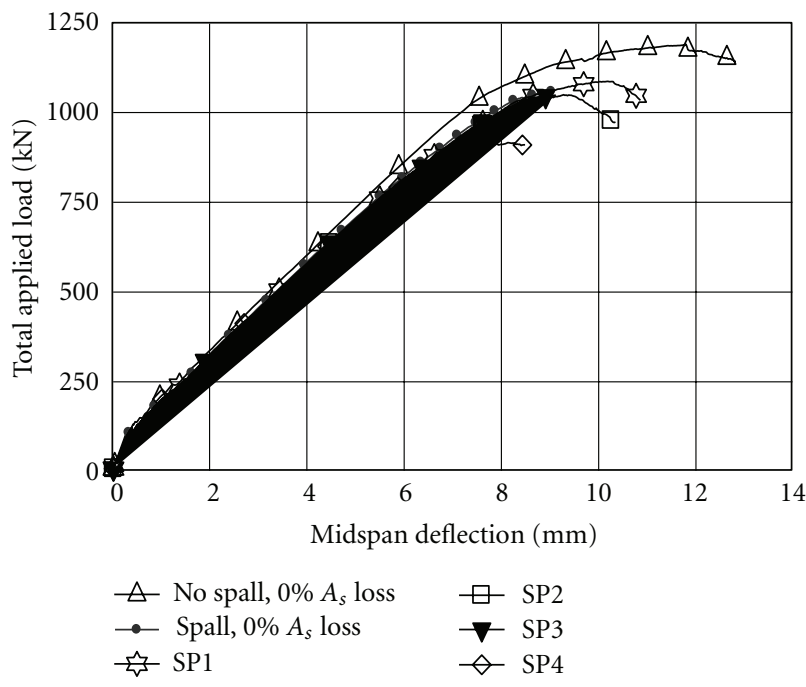

FIGURE 13: FE predicted load-deflection response for models with spatially distributed, local maximum section loss in stirrups.

to $100 \%$. The significance of the beam width and uniform cross-sectional area loss to the energy absorbed for the models is shown in Figure 11(b). When concrete cover spalling occurs, the energy absorbed was $40 \%$ less than for the undamaged model for the cases with no area loss. When the uniform section loss increases, the difference between the energies for the model without spalling and the model with spalling was reduced to $24 \%$ for $50 \%$ uniform cross-sectional area loss, and almost no difference for $100 \%$ uniform crosssectional area loss. For the $100 \%$ uniform cross-sectional

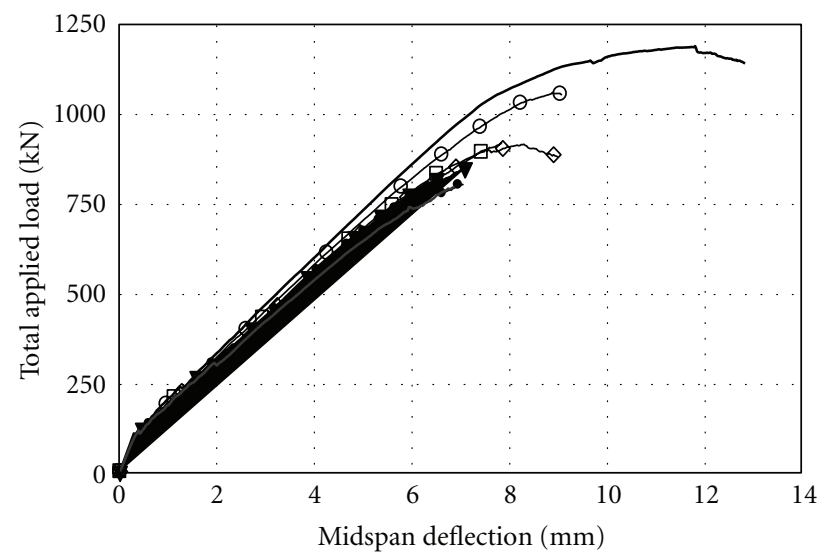

- No spall, $0 \% A_{s}$ loss, bonded
- - Spall, $0 \% A_{s}$ loss, bonded
$\square$ Spall, $0 \% A_{s}$ loss, debonded
$\multimap$ Spall, $50 \% A_{s}$ loss, debonded
$\longrightarrow$ SP2, $0 \%$ uniform and $75 \%$ local, debonded
$\rightarrow-$ SP2, $50 \%$ uniform and $75 \%$ local, debonded
- Spall, $100 \% A_{s}$ loss

FIGURE 14: FE predicted load-deflection response for models with fully debonded concrete-rebar interface.

area loss models, insignificant differences were observed for both the ultimate strength and energy due to spalling, and the combined damage results were about $33 \%$ and $65 \%$ lower, respectively, than those of the undamaged model. The analysis results are summarized in Table 1.

Actual corroded stirrups may contain both uniform cross-sectional area loss along the length and locally severe 


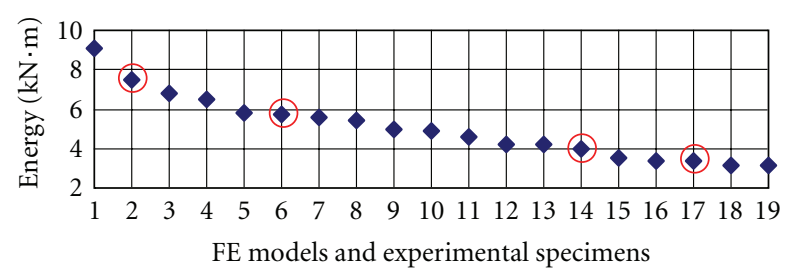

(a)

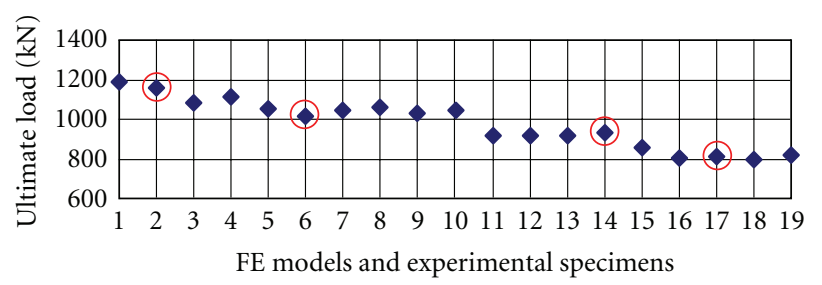

$\begin{array}{ll}\text { 1- No spall, 0\% } A_{s} \text { loss } & \text { 11- Spall, 50\% } A_{s} \text { loss, debonded } \\ \text { 2- Specimen 10RA } & \text { 12- Spall, } 0 \% A_{s} \text { loss, debonded } \\ \text { 3- SP1 } & \text { 13- SP4 } \\ \text { 4- No spall, 50\% } A_{s} & \text { 14- Specimen 10RC } \\ \text { 5- SP2 } & \text { 15- SP2 (0\% unif., 75\% local), debonded } \\ \text { 6- Specimen 10RB } & \text { 16- SP2 (50\% unif., 75\% local), debonded } \\ \text { 7- SP3 } & \text { 17- Specimen 10RD } \\ \text { 8- Spall, 0\% } A_{s} \text { loss } & \text { 18- Spall, 100\% } A_{s} \text { loss } \\ \text { 9- Spall, 50\% } A_{s} \text { loss } & \text { 19- No spall, } 100 \% A_{s} \text { loss } \\ \text { 10- No spall, } 0 \% A_{s} \text { loss, debonded }\end{array}$

Experimental specimen

(b)

FIGURE 15: Summary results for maximum load and energy.

cross-sectional area loss at discrete locations along the rebar due to concentrated corrosion or pitting. For this study, this is referred to as maximum cross-sectional area loss. An FE model with concrete spalling was employed to determine the effects of locally reduced stirrup areas on structural performance. In this model, each stirrup was modeled using nine finite truss elements. A local maximum cross-sectional area loss of $75 \%$ (corresponding to $25 \%$ of the original stirrup area) was applied to one of the nine finite truss elements, with the full cross-sectional stirrup area for the other eight truss elements. Different locations for the local maximum cross-sectional area loss within the test span were considered to assess the influence of spatial damage sequencing on ultimate loads, energy, and crack patterns. Due to the use of symmetry in the modeling, the analysis implies that the opposite leg of the same stirrup (not directly modeled) has the maximum area loss in the same location, corresponding to a worst-case situation. Four models with different locations of local maximum loss were developed and designated as SP1, SP2, SP3, and SP4, as shown in Figure 12.

Locations of stirrups and maximum stirrup area loss are shown with a dashed line and a circle, respectively, in this figure. For these models, the concrete cover was removed, as it would be likely that for this level of stirrup corrosion damage, the cover would have spalled significantly. The analyses were performed and the maximum load, deflection
TABLE 3: Summary results for finite element models with spatially distributed, local maximum cross-sectional loss in stirrups.

\begin{tabular}{lccc}
\hline Model & $\begin{array}{c}\text { Max. load } \\
(\mathrm{kN})\end{array}$ & $\begin{array}{c}\text { Deflection at max. } \\
\text { load }(\mathrm{mm})\end{array}$ & $\begin{array}{c}\text { Energy } \\
(\mathrm{kN} \cdot \mathrm{m})\end{array}$ \\
\hline SP1 & 1087 & 10.2 & 6.8 \\
SP2 & 1050 & 9.3 & 5.8 \\
SP3 & 1049 & 9.0 & 5.6 \\
SP4 & 919 & 7.7 & 4.2 \\
\hline
\end{tabular}

at the maximum load, and energy results for the models are summarized in Table 3. Vector plots of maximum principal strains (taken when maximum principal strain reaches approximately 0.03 anywhere in concrete cross-sections) were used for the comparison of possible crack patterns, as shown in Figure 12. Localized damage as indicated by rebar crosssectional area loss can alter the crack pattern as shown in the figure by the comparison of the principal tensile strains of the SP1, SP2, SP3, and SP4 models with the model with spalling and no localized section loss.

Load-deflection responses of the models are shown in Figure 13. Ultimate loads in Table 3 for the SP1, SP2, and SP3 models were similar to each other and close to that of the model with concrete spalling, no stirrup area loss, and a bonded concrete-rebar interface (2\% higher for SP1 model and 1\% less for SP2 and SP3 models). Energies of the SP1, SP2, and SP3 models were higher than for the model with concrete spalling and no area loss, $24 \%, 5 \%$, and $2 \%$ larger, respectively. The ultimate load and energy of the SP4 model were $13 \%$ and $23 \%$ lower, respectively, than those of the model with spalling and no localized section loss. The SP4 model exhibited the lowest ultimate load and energy among the local section loss models. For this model, the two locations of local maximum section loss were near or within the area of the beam with large principal strains and at midheight of the beam, away from the constraint provided by the flexural steel and the compression zone (Figure 12). The sequencing of damage within this region contributed to diminished capacity, and energy as the locally reduced sections in the compression strut zone failed to adequately constrain the transverse tensile strains. These results indicate that the location of stirrup corrosion damage may affect the member behavior and that damage sequencing could be of significance. For randomly occurring damage in the field, the likelihood of sequencing may be small. However, for situations where diagonal cracks already exist from previous loads as well as shrinkage and temperature effects, corrosion may concentrate at the stirrups crossing the crack due to the availability of moisture, air, and chlorides.

The correlation of uniform and localized section loss will vary with the amount of cover damage, cracking of the concrete, and the environmental conditions along the specimen. For sections with significant amounts of cover spalling, it is likely that large localized cross-sectional area loss will occur simultaneously with uniform cross-sectional area loss along the stirrup leg length. When uniform cross-sectional area loss in the stirrups was combined with local maximum stirrup cross-section loss, the capacity and energy of the models were 


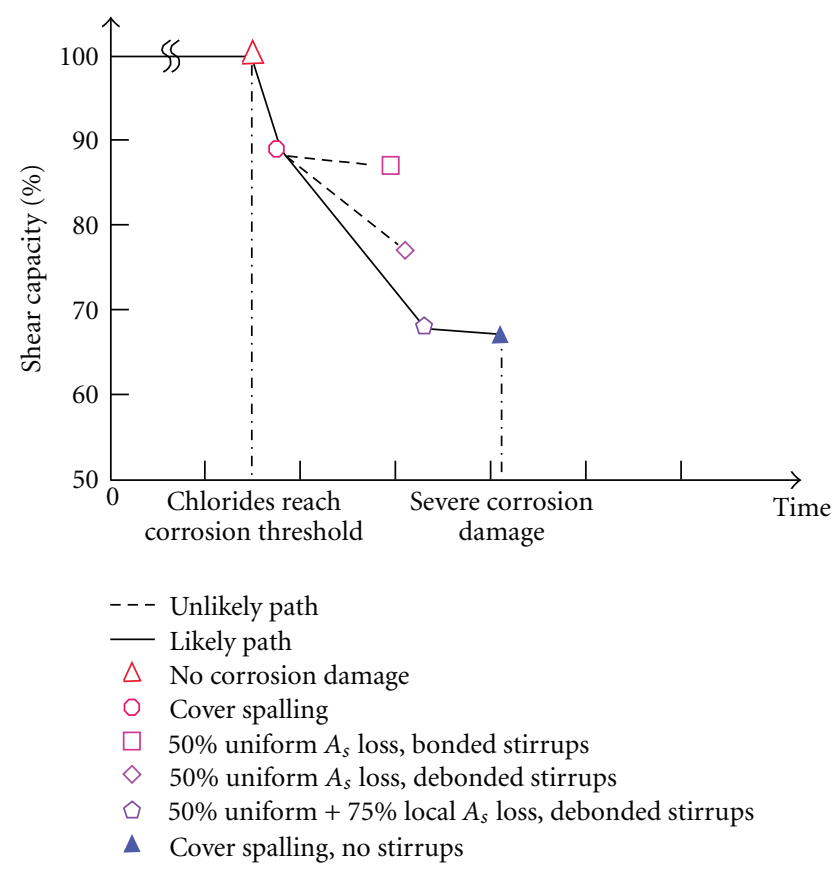

FIgURE 16: Corrosion damage sequence as a function of shear capacity.

only slightly reduced when the stirrups are debonded from the concrete. However, when stirrups are debonded from the concrete, load and deformation capacity were significantly reduced as shown for model SP2 with and without stirrup bond to the concrete in Table 1.

Concrete cover spalling diminishes the bond at the concrete-rebar interface. As the bond between the concrete and steel reduces, the strains become more uniform over the height of the stirrups. To assess this phenomenon, a combination of cover spalling and concrete-rebar interface debonding was included in a series of analyses. The model with concrete spalling included stirrups modeled using nine truss elements with ten nodes. All the nodes for the stirrup elements were constrained to solid concrete element nodes where they were coincident. To simulate concreterebar interface debonding due to corrosion, only the two outer nodes of the stirrup element groups at the ends were connected to the concrete elements. Analyses were performed and results (Table 1) for ultimate load and energy of the models with spalled concrete cover, $0 \% A_{s}$ loss, and debonded stirrups were $13 \%$ and $23 \%$ lower, respectively, than those of the otherwise similar model with bonded stirrups. Subsequently, a uniform stirrup cross-sectional area loss of $50 \%$ was added to the spalled concrete cover model with debonded concrete-rebar interface. This model produced an ultimate load reduction of $23 \%$ and an energy loss of 50\% compared to the undamaged model. Debonded interfaces were then included for the local maximum section loss using the SP2 damage sequencing (uniform section loss of $0 \%$ and local maximum section loss of $75 \%$ ). This SP2 model with concrete-rebar interface debonding had capacity and energy reductions of $28 \%$ and $62 \%$, respectively, compared to the undamaged model, and had capacity and energy reductions of $19 \%$ and $40 \%$, respectively, compared to the similar SP2 model with bonded stirrups of the same cross-sectional areas. An FE model considering concrete spalling, concrete-rebar interface debonding, uniform rebar section loss of $50 \%$, and local maximum rebar section loss of $75 \%$ for the SP2 model was also developed. Ultimate capacity and energy of the model were $32 \%$ and $63 \%$ less, respectively, than those of the undamaged model. This damage combination corresponded to the most severe corrosion damage state observed in experimental specimens (specimen 10RD). Load-deflection responses of the models with debonded concrete-rebar interfaces are shown in Figure 14, and analysis results are summarized in Table 1. As seen in this figure, the maximum loads of the models with the debonded concreterebar interfaces are relatively close to each other and ranged between $23 \%$ and $32 \%$ less than for the undamaged model. Sequencing of locations of maximum section loss may not be as important when debonding occurs, as the stirrup strains are concentrated within the smallest stirrup area, independent of the location relative to the principal tensile strains on the cross-section.

Summary results of ultimate loads and energies for all finite element analyses and experimental data are shown in Figure 15. The sequence of results is sorted by the amount of energy and by the capacity. Analysis results fall within the range of the experimental findings. A progression of corrosion damage and the subsequent capacity loss for the test specimens was developed considering the damage to the concrete and stirrups that occurs concurrently and based on the analytically predicted capacity loss from individual and combined damage components. Predicted sequencing of damage is illustrated in Figure 16 using a pseudotime progression for corrosion damage as a function of shear capacity. Corrosion damage initiates when chlorides reach corrosion threshold. Time to reach this threshold varies but depends on concrete permeability, as well as the availability of moisture, chlorides, and oxygen. At the initiation of corrosion, the stirrups begin to lose cross-sectional area, and the expansion of the corrosion products results in concrete cover damage. Relatively small reinforcing steel area loss (experimentally observed nominal section loss of an average of $2.9 \%$ of initial area $[10,11]$ ) was required to produce cover cracking and initiate spalling. Loss of the concrete cover immediately reduced the capacity due to the reduction in the beam cross-section, even as the stirrup area is close to the original undamaged area. Initial concrete cover damage was followed by additional steel area reduction (both uniform and localized area loss) and debonding of the concreterebar interface along the length of the stirrups. The stirrup location with the greatest localized section loss limits the shear capacity, particularly for debonded stirrup legs, which concentrates strain in the reduced section of the stirrup regardless of the location of the reduced area. This type of cumulative corrosion damage was represented by the severe damage state observed for the experimental specimens and was reasonably modeled by combining the individual corrosion damage components. 


\section{Conclusions}

Engineers often must evaluate corrosion-damaged, conventionally reinforced concrete structures. Visual inspections of steel-reinforced concrete members with corrosion damage may not adequately indicate the actual structural performance. Estimating the remaining shear capacity requires analysis methods that can incorporate the effects of corrosion damage to the stirrups and to the concrete section. The use of finite element (FE) analysis has become routine for structural engineers and permits refined analyses and was used to determine the impact of corrosion damage components on capacity for shear critical beams. Analyses were correlated with large-scale experimental specimens subjected to accelerated corrosion of the embedded stirrups. Based on observed corrosion damage to the experimental specimens, damage parameters included in the analytical study were concrete section loss due to cover spalling, uniform rebar cross-sectional loss, localized maximum rebar cross-sectional loss and corresponding spatial distribution of maximum loss, and debonding of corrosion-damaged stirrups from the concrete. Based on FE analysis results, the following conclusions are made.

(1) The range of damage observed for the experimental specimens was bounded within the analytically superimposed corrosion damage parameters.

(2) FE results and experimental data show that corrosion damage reduced the stiffness in the service range, load-carrying capacity, and deflection at the maximum load of the reinforced concrete beam specimens.

(3) For the section considered, loss of bond between the stirrups and concrete produced the greatest reduction in load and deformation capacity for an individual damage component.

(4) Cover spalling reduced the load-carrying capacity by $11 \%$ and the energy by $40 \%$ compared with the undamaged specimen. The contribution of the cover to strength and deformation capacity may depend on the relative size of the cover area to the overall size of the specimen.

(5) Uniform section loss up to $50 \%$ of the original area had relatively small impact on strength although the energy was reduced by $29 \%$. When the stirrup area was reduced to zero, both the load and deformation capacity were significantly reduced.

(6) The spatial distribution of localized cross-sectional area loss (local maximum section loss) can alter the crack pattern compared with the undamaged model when the stirrups are still effectively bonded to the surrounding concrete. When the maximum area loss corresponds to a region of the beam with large principal tensile stresses, the capacity is reduced.

(7) The location of the maximum stirrup section loss becomes less important when stirrup debonding occurs. Unbonded stirrup strains are largest within the reduced section regardless of location relative to diagonal cracks.

(8) Combined damage parameters of cover loss, uniform area loss, locally reduced areas, and stirrup debonding effectively represented the experimental specimen in the most severe corrosion damage state.

\section{References}

[1] A. A. Almusallam, A. S. Al-Gahtani, A. R. Aziz, F. H. Dakhil, and Rasheeduzzafar, "Effect of reinforcement corrosion on flexural behavior of concrete slabs," Journal of Materials in Civil Engineering, vol. 8, no. 3, pp. 123-127, 1996.

[2] G. J. Al-Sulaimani, M. Kaleemullah, I. A. Basunbul, and Rasheeduzzafar, "Influence of corrosion and cracking on bond behavior and strength of reinforced concrete members," ACI Structural Journal, vol. 87, no. 2, pp. 220-231, 1990.

[3] J. G. Cabrera, "Deterioration of concrete due to reinforcement steel corrosion," Cement and Concrete Composites, vol. 18, pp. 47-59, 1996.

[4] P. S. Mangat and M. S. Elgarf, "Strength and serviceability of repaired reinforced concrete beams undergoing reinforcement corrosion," Magazine of Concrete Research, vol. 51, no. 2, pp. 97-112, 1999.

[5] L. Amleh and S. Mirza, "Corrosion influence on bond between steel and concrete," ACI Structural Journal, vol. 96, no. 3, pp. 415-423, 1999.

[6] K. Stanish, R. D. Hooton, and S. J. Pantazopoulou, "Corrosion effects on bond strength in reinforced concrete," ACI Structural Journal, vol. 96, no. 6, pp. 915-921, 1999.

[7] A. A. Almusallam, "Effect of degree of corrosion on the properties of reinforcing steel bars," Construction and Building Materials, vol. 15, pp. 361-368, 2001.

[8] R. Palsson and M. S. Mirza, "Mechanical response of corroded steel reinforcement of abandoned concrete bridge," ACI Structural Journal, vol. 99, no. 2, pp. 157-162, 2002.

[9] W. C. Farrow III, Shear capacity assessment of corrosion-damaged reinforced concrete beams, M.S. thesis, Department of Civil, Construction and Environmental Engineering, Oregon State University, Corvallis, Ore, USA, 2002.

[10] C. Higgins and W. C. Farrow III, "Tests of reinforced concrete beams with corrosion-damaged stirrups," ACI Structural Journal, vol. 103, no. 1, pp. 133-141, 2006.

[11] C. Higgins, F. C. William III, T. Potisuk et al., "Shear capacity assessment of corrosion-damaged reinforced concrete beams," Tech. Rep. FHWA-OR-RD-04-06, Federal Highway Administration, Washington, DC, USA, 2003.

[12] M. Suidan and W. C. Schnobrich, "Finite element analysis of reinforced concrete," Journal of the Structural Division, vol. 99, no. 10, pp. 2109-2122, 1973.

[13] N. J. Stevens, S. M. Uzumeri, and M. P. Collins, Analytical Modelling of Reinforced Concrete Subjected to Monotonic and Reversed Loadings, Publication no. 87-1, Department of Civil Engineering, University of Toronto, Toronto, Canada, 1987.

[14] F. J. Vecchio, "Nonlinear finite element analysis of reinforced concrete membranes," ACI Structural Journal, vol. 86, no. 1, pp. 26-35, 1989.

[15] P. Bhatt and M. Abdel Kader, "Prediction of shear strength of reinforced concrete beams by nonlinear finite element analysis," Computers and Structures, vol. 68, no. 1-3, pp. 139-155, 1998. 
[16] K. Maekawa, A. Pimanmas, and H. Okamura, Nonlinear Mechanics of Reinforced Concrete, Spon Press, New York, NY, USA, 2003.

[17] T. Potisuk, Analysis of conventionally reinforced concrete deck girder bridges for shear, Ph.D. thesis, Department of Civil, Construction and Environmental Engineering, Oregon State University, Corvallis, Ore, USA, 2004.

[18] H. J. Dagher and S. Kulendran, "Finite element modeling of corrosion damage in concrete structures," ACI Structural Journal, vol. 89, no. 6, pp. 699-708, 1992.

[19] D. Coronelli and P. Gambarova, "Structural assessment of corroded reinforced concrete beams: modeling guidelines," Journal of Structural Engineering, vol. 130, no. 8, pp. 12141224, 2004.

[20] Oregon Department of Transportation, Bridge Inspection Pocket Coding Guide, Oregon Department of Transportation, Salem, Ore, USA, 2001.

[21] Federal Highway Administration, "Recording and coding guide for the structure inventory and appraisal of the nation's bridges," Tech. Rep. FHWA-PD-96-001, Federal Highway Administration, Washington, DC, USA, 1995.

[22] “ANSYS user's manual revision 7.1," ANSYS, Inc., Canonsburg, Pa, USA, 2003.

[23] C. E. Todeschini, A. C. Bianchini, and C. E. Kesler, "Behavior of concrete columns reinforced with high strength steels," ACI Journal Proceedings, vol. 61, no. 6, pp. 701-716, 1964.

[24] M. T. M. Soliman and C. W. Yu, "The flexural stress-strain relationship of concrete confined by rectangular transverse reinforcement," Magazine of Concrete Research, vol. 19, no. 61, pp. 223-238, 1967.

[25] D. C. Kent and R. Park, "Flexural Members with Confined Concrete," Journal of the Structural Division, vol. 97, no. 7, pp. 1969-1990, 1971. 

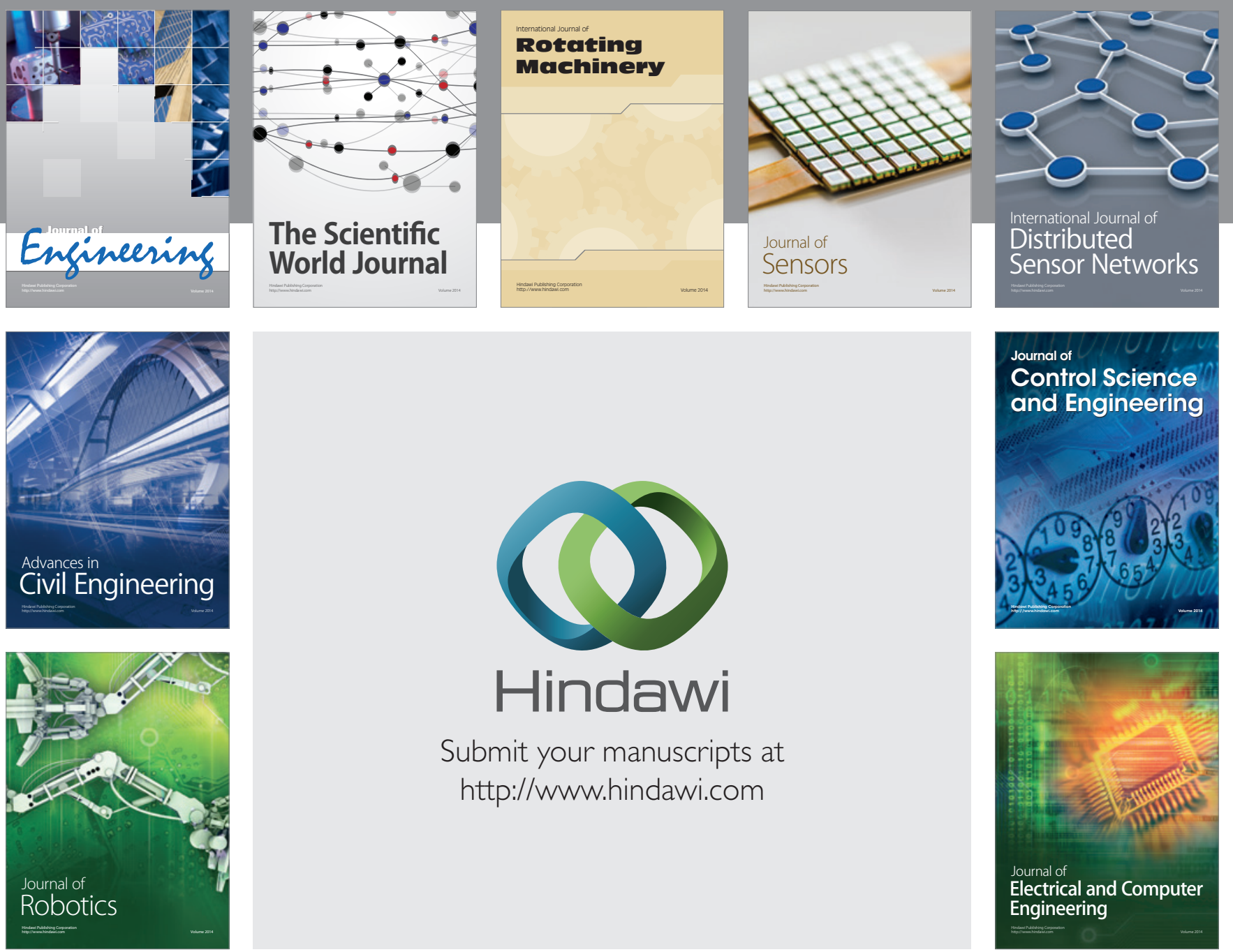

Submit your manuscripts at

http://www.hindawi.com
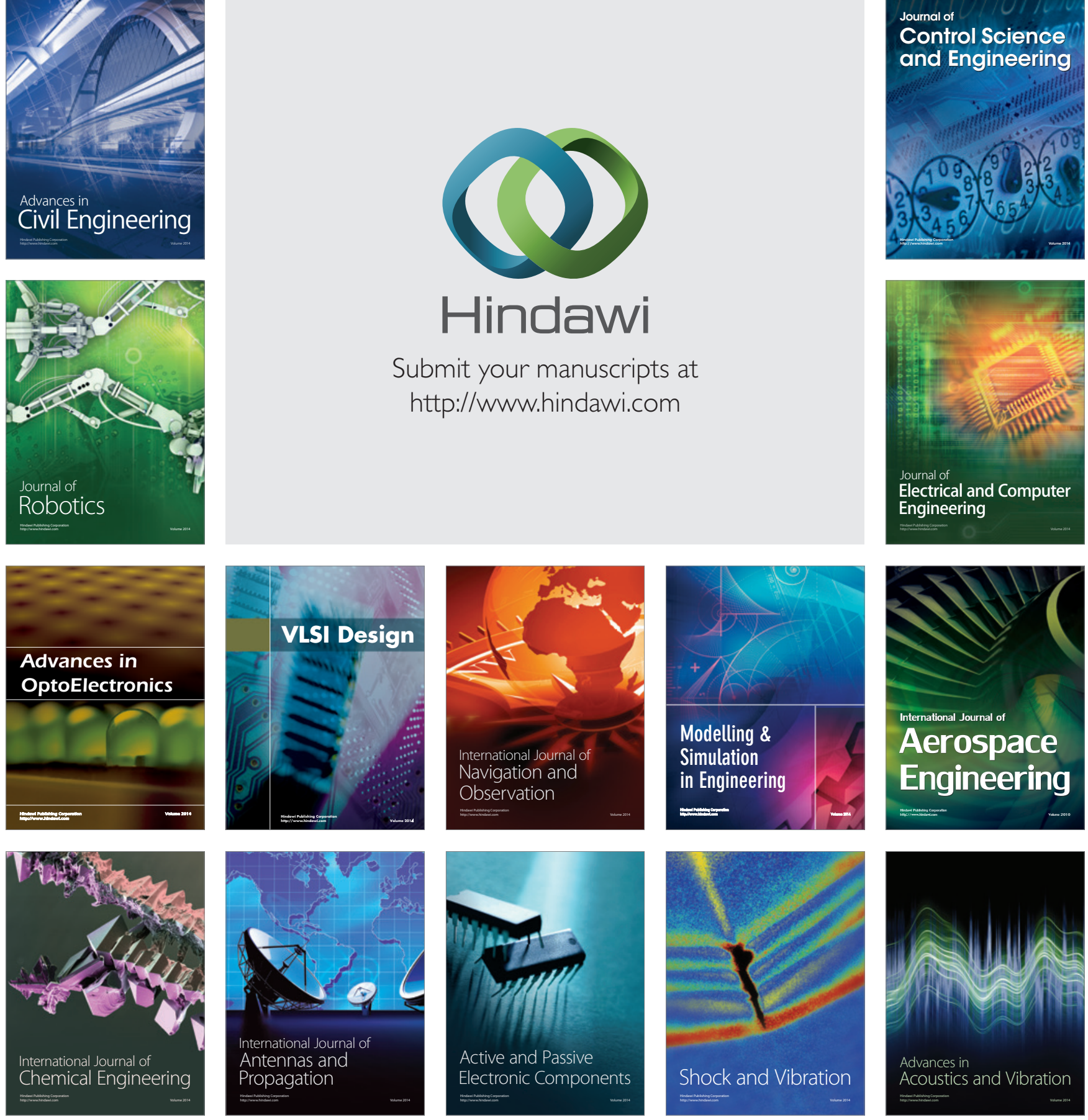